\title{
Amino Acid Sequence Prerequisites for the Formation of $c_{n}$ Ions
}

\author{
Kevin M. Downard and Klaus Biemann \\ Department of Chemistry, Massachusetts Institute of Technology, Cambridge, Massachusetts, USA
}

\begin{abstract}
Amino acid sequence prerequisites are described for the formation of $c_{n}$ ions observed in high-energy collision-induced decomposition spectra of peptides. It is shown that the formation of $c_{n}$ ions is promoted by the nature of the amino acid C-terminal to the cleavage site. A propensity for $c_{n}$ cleavage preceding threonine, and to a lesser extent tryptophan, lysine, and serine, is demonstrated where fragmentation is directed $\mathrm{N}$-terminally at these residues. In addition, the nature of the residue N-terminal to the cleavage site is shown to have little effect on $c_{n}$ ion formation. A mechanism for $c_{n}$ ion formation is proposed and its applicability to the results observed is discussed. (J Am Soc Mass Spectrom 1993, 4, 874-881)
\end{abstract}

$\mathrm{T}$ The ability to ionize large, polar molecules using methods such as fast-atom bombardment (FAB) [1], and the subsequent development of mass spectrometers capable of analyzing such species, have made it possible to structurally characterize important biomolecules previously not amenable to the mass spectrometric technique.

Mass spectrometry is now well established as a sensitive and reproducible approach to peptide sequencing [2-5]. Under the appropriate conditions, peptides have been shown to dissociate within a mass spectrometer along predictable pathways, often accompanied by hydrogen rearrangement $[6-8]$. It has been realized for some time, however, that under highenergy conditions, fragment ions observed in the conventional $F \wedge B$ mass spectrum are quite distinct from those seen in the corresponding collision-induced dissociation (CID) spectrum [9].

A conventional FAB spectrum, when obtained with sufficient peptide sample, can exhibit fragment ions in addition to an intact precursor ion $[\mathrm{M}+\mathrm{H}]^{+}$, albeit, of low relative abundance. In these spectra, consecutive series of several fragments of the type $a_{n}, b_{n}, c_{n}$, and $y_{n}$ (the nomenclature is a variant [8] of that originally proposed by Roepstorff and Fohlman [10]) are frequently observed. The interpretation of a conventional FAB spectrum, however, is complicated by the weak ion signals and the appearance of interfering matrix ions, particularly in the low-mass region of the spectrum.

Peptides are sequenced with much greater ease and confidence within a tandem magnetic-sector mass spectrometer, where the ${ }^{12} \mathrm{C}$-only component of the $[\mathrm{M}+\mathrm{H}]^{+}$precursor ion is selected solely for collision

Address reprint requests to Prof. Klaus Biemann, Department of Chemistry, Room 56-010, Massachusetts Institute of Technology, Cambridge, MA 02139-4307. with an inert neutral molecule. This imparts additional energy onto the precursor ion, resulting in the formation of fragment ions of greater relative abundance. The resulting CID spectrum generally contains a more complete series of ions of few sequence types with no matrix background, provided the precursor ion signal is strong relative to the background and does not have the same mass as that of a matrix cluster ion [11]. The sequence ions observed are structure-specific; that is, they are influenced in part by the nature of the peptide. It has been noted that a basic amino acid residue at or near the N-terminus generally results in the formation of fragment ions in which the N-terminus retains the charge [9]. Conversely, a basic amino acid toward the C-terminus favors the formation of $C$ terminal fragment ions. However, the structural prerequisites necessary to "drive" a specific fragmentation remain poorly understood.

One striking difference between conventional FAB and CID mass spectra is the occurrence of N-terminal $\mathrm{c}_{\mathrm{n}}$ ions. These ions are formed by the cleavage of $N-C$ bond of a peptide backbone such that the $\mathrm{N}$-terminus retains the proton from the $[\mathrm{M}+\mathrm{H}]^{+}$precursor ion and a hydrogen atom is transferred from the neutral C-terminal fragment (Figure 1). For reasuns that have been explained elsewhere [8], we prefer to designate the product ion " $c_{n}$ " rather than that proposed by Roepstorff and Fohlman [10].

$C_{n}$ ions are observed commonly in FAB spectra, often as a consecutive ion series, but appear sporadically in CID spectra. This led us to surmise that their formation under CID conditions may be more sequence-dependent than the remainder of the backbone fragment ions. Consequently, $c_{n}$ ions may provide a means to elucidate or at least verify a peptide's structure when sequence ambiguities exist.

Since the relative abundances of the fragment ions in a CID spectrum are dependent both on the 

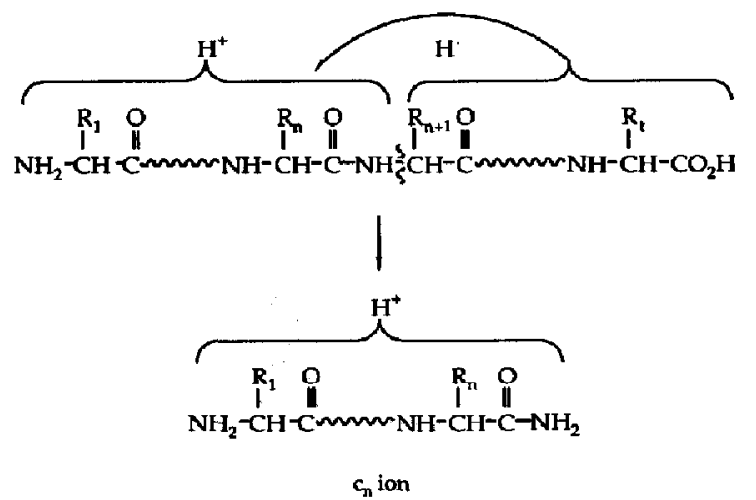

Figure 1. Fragmentation of a protonated peptide giving rise to a $c_{\mathrm{n}}$ ion.

collision-activation conditions employed [12, 13] and the sequence of amino acids in the peptide, it is necessary to operate at constant collision-activation conditions to investigate the effect a peptide's structure has on its fragmentation. We examined, then, the appearance of $c_{n}$ ions by studying in detail 168 good quality CID spectra of peptides (with molecular weights ranging from 400 to 2500) recorded under high-energy collision-activation conditions on a tandem magneticsector mass spectrometer. This article describes the results of this study, which follows a preliminary report [14].

\section{Experimental}

All of the CID spectra used in this study were recorded on a JEOL $\mathrm{HX110} / \mathrm{H} \times 110$ high-resolution tandem magnetic-sector mass spectrometer of $E_{1} B_{1} E_{2} B_{2}$ geometry operating at an accelerating voltage of $10 \mathrm{kV}$. Peptides were dissolved in a suitable FAB matrix, typically glycerol or 3-nitrobenzyl alcohol, and bombarded with Xe atoms (JEOL FAB gun at $6 \mathrm{kV}$ ) or $\mathrm{Cs}^{+}$ ions (JEOL $\mathrm{Cs}^{+}$ion gun at $25 \mathrm{kV}$ ). The resolution of MS-I was set to transmit only the ${ }^{12} \mathrm{C}$ component of the $\left[\mathrm{M}+\mathrm{H}^{+}\right.$precursor ions to the collision region. These ions were collided with helium gas in the third fieldfree region (between $B_{1}$ and $E_{2}$ ) at a pressure sufficient to reduce the primary beam by $\sim 70 \%$. A collision cell potential of $3 \mathrm{kV}$ was applied to record the majority of the CID spectra to improve transmission of the lowmass fragment ions. The remainder of the spectra (approximately 20\%) were recorded with a grounded cell. The possibility that low-mass $c_{n}$ ions may not be detected in spectra recorded with a grounded cell is not thought to adversely affect the results of this study in view of the small fraction of spectra recorded under these conditions. The resolution of MS-II was typically set to $1: 1000$.

A solution of ARVTAL (3.1 $\mu \mathrm{g}, 5 \mathrm{nmol})$ in deuterium oxide $(5 \mu \mathrm{l})$ with triethylamine $(0.3 \mu 1,5 \mu \mathrm{mol})$ (pH 11) was heated at $50{ }^{\circ} \mathrm{C}$ with agitation for four days. The solution was dried in a centrifuge under vacuum. The product was dissolved in $\mathrm{d}_{8}$-glycerol and introduced into the ion source of the mass spectrometer.

\section{Results and Discussion}

The sporadic occurrence of $c_{n}$. ions in high-energy CID spectra is illustrated for the peptide $\alpha$-neurokinin (HKTDSFVGLM-NH ${ }_{2}$ ). For the purpose of comparison, its conventional FAB mass spectrum (Figure $2 \mathrm{a}$ ) shows an almost complete series of $c_{n}$ ions, yet the low-mass region of the spectrum is dominated by matrix ions, which may obscure the detection of $c_{1}$ and $c_{2}$. This contrasts the CID spectrum of protonated $\alpha$-neurokinin (Figure $2 b$ ) which, despite a complete series of $N$-terminal $b_{n}$ ions and a partial series of $a_{n}$ ions, exhibits only three $c_{n}$ ions $\left(c_{1}, c_{2}\right.$, and $\left.c_{4}\right)$.

In view of the mechanism of Figure 1, two criteria are important for the formation of $c_{n}$ ions: (1) the peptide should have a basic amino acid towards its $\mathrm{N}$-terminus to retain the proton and direct the fragmentation $\mathrm{N}$-terminally, and (2) a hydrogen atom should be transferred from the C-terminal portion of the peptide to the $\mathrm{N}$ atom at the cleavage site. Intuitively, it would appear likely that a neighboring group to the $c_{n}$ cleavage site should act as the hydrogen atom donor, perhaps the amino acid side chain of the residue $\left(X_{n+1}\right)$ immediately following the cleavage site. To explore this assertion, 168 high-energy CID spectra were studied to correlate the occurrence of $c_{n}$ ions with the identity of the neighboring amino acid residue (residue $X_{n+1}$ of Figure 1) toward the C-terminus. These data are summarized in Table 1.

Column I lists the total number of times that each amino acid residue occurs in the peptides studied. This column excludes the number of times that each residue $\mathrm{X}$ is at the $\mathrm{N}$-terminus since these residues cannot reside $C$-terminal to a $c_{n}$ cleavage site. Column II lists the total number of times that a $c_{n}$ ion was actually observed preceding each residue $x_{n+1}-A c_{n}$ ion was assigned to a fragment peak of a CID spectrum where the mass of the ion observed was within $0.5 \mathrm{Da}$ (though the mass accuracy was often better than $\pm 0.3 \mathrm{Da}$ ) of that predicted from the peptide's structure. In addition, the intensity of the ion had to be sufficient so that the ion signal could be easily discerned from the baseline of the spectrum. In this regard, each spectrum was assessed visually, and no arbitrary "cut-off" intensity was imposed. The values in parentheses in columr II denote the number of questionable assignments of the total specified. Questionable assignments are those in which a peak corresponding to a $c_{n}$ ion can be equally well assigned to another fragment ion and/or has a peak height approaching the noise level in the spectrum. Column III lists the number of times a $c_{n}$ ion is observed preceding residue $\mathrm{X}_{\mathrm{n}+1}$ at the C-terminus, where a competing hydrogen transfer from the terminal carboxyl group is possible. Column IVa specifies 

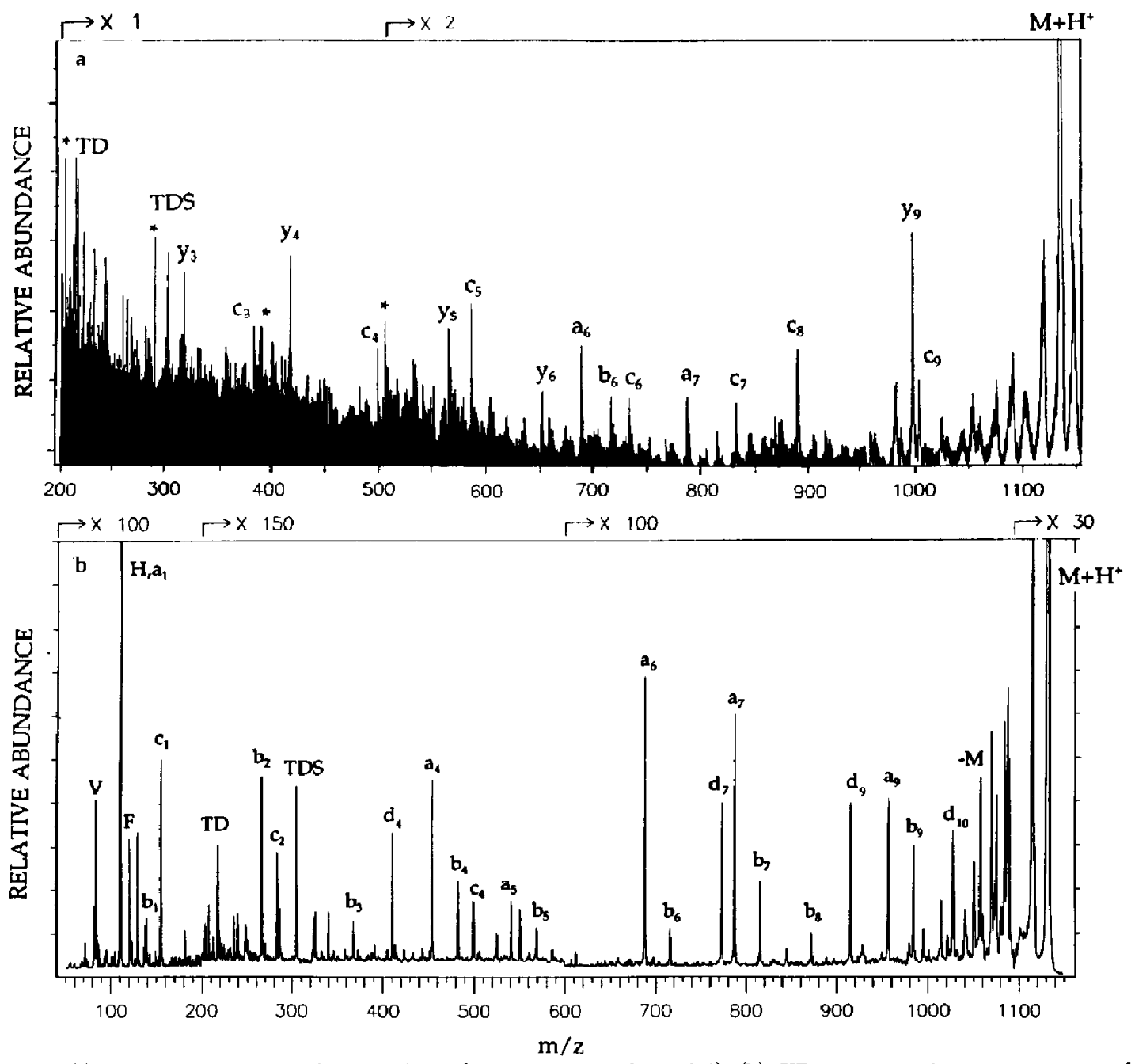

Figure 2. (a) FAB mass spectrum of $\alpha$-neurokinin (matrix ions are denoted *); (b) CID spectrum of protonated $\alpha$-neurokinin (HKTDSFVGLM-NH ${ }_{2}$ ).

the probability (as a percentage) that a residue $X_{n+1}$ resides C-terminal to a $\varepsilon_{n}$ cleavage site. Column IVb corrects the data of column IVa by taking into account the values of column III.

The data summarized in Table 1 allow the 20 common protein amino acids to be ranked in descending order relative to the probability that each is the Cterminal neighbor to the cleavage site. It should be noted that this order changes little regardless of whether residues occurring at the C-terminus are corrected for, or whether the questionable assignments are included in, the data set. Consequently, for simplicity, the amino acid residues have been ranked without the inclusion of questionable assignments and have been corrected for C-terminal residues (Figure 3).

It is important to note at this stage, that the specific order of amino acids is somewhat influenced by the sample of CID spectra chosen for this study. Nevertheless, it is believed that the large number of spectra, and the resulting variety of sequences, are sufficient so that no significant changes to the order would be observed if a different, or much larger, sample sel were to be used.

Of the 20 residues ranked in Figure $3, c_{n}$ cleavage occurs at over $50 \%$ of the potential siles preceding only one of them, namely, threonine. Cleavage occurs at between $20-50 \%$ of the potential sites to yield a $c_{n}$ ion when the fragmentation site is followed by any of the next three residues: tryptophan, lysine, and serine. With the exception of cysteine and asparagine, the remaining residues appear to promote $c_{n}$ ion formation at less than $10 \%$ of the potential sites, and thus their respective positions in the ranking are less relevant. 
Table 1. Data correlating the occurrence of $c_{n}$ ions with the identity of the amino acid residue $\mathrm{X}_{n+1} \mathrm{C}$-terminal to the cleavage site

\begin{tabular}{|c|c|c|c|c|c|}
\hline \multirow[b]{2}{*}{ Residue $\mathrm{X}$} & \multirow{2}{*}{$\begin{array}{c}\text { I } \\
\text { No. of times } \\
\text { residue } \mathrm{X} \text { occurs } \\
\text { in all peptides } \\
\text { studied } \\
\text { (excluding the } \\
\text { N-terminus) }\end{array}$} & \multirow{2}{*}{$\begin{array}{l}\text { No. of times a } c_{n} \\
\text { ion is observed } \\
\text { preceding } \\
\text { residue } X \text { at } \\
\text { position } n+1^{*}\end{array}$} & \multirow{2}{*}{$\begin{array}{l}\text { Of II, no. of } \\
\text { times a } c_{n} \text { ion is } \\
\text { observed } \\
\text { preceding } \\
\text { residue } X \text { at the } \\
\text { C-terminus* }\end{array}$} & \multicolumn{2}{|c|}{$\begin{array}{c}\text { IV } \\
\text { Probability (as a } \% \text { ) of } \\
c_{n} \text { ion formation } \\
\text { preceding residue } X \text { at } \\
\text { position } n+1 \text { (excl. } \\
\text { questionable } \\
\text { assignments) }\end{array}$} \\
\hline & & & & $\begin{array}{c}\text { IVa } \\
\text { (II } /) \times 100\end{array}$ & $\begin{array}{c}\text { IVb } \\
\text { (III-III } /) \times 100\end{array}$ \\
\hline A (Ala) & 121 & $8(1)$ & $2(0)$ & 5.8 & 4.1 \\
\hline C (Cys) & 24 & $3(0)$ & $0(0)$ & 12.5 & 12.5 \\
\hline$D$ (Asp\}) & 76 & $10(2)$ & $2(0)$ & 10.5 & 7.9 \\
\hline E (GIU) & 112 & $9(3)$ & $3(2)$ & 5.4 & 4.5 \\
\hline F (Phe) & 74 & $7(2)$ & $o(0)$ & 6.8 & 6.8 \\
\hline G (Gly) & 115 & $8(2)$ & $1(1)$ & 5.2 & 5.2 \\
\hline$H$ (His) & 36 & $2(1)$ & $O(0)$ & 2.8 & 2.8 \\
\hline I (lle) & 56 & $1(0)$ & $\alpha(0)$ & 1.8 & 1.8 \\
\hline$K$ (Lys) & 79 & $27(4)$ & $6(2)$ & 29.1 & 24.1 \\
\hline L (Leu) & 154 & $17(2)$ & $4(2)$ & 9.7 & 8.4 \\
\hline M (Met) & 29 & $1(0)$ & $1(0)$ & 3.4 & 0 \\
\hline$N($ Asn) & 39 & $5(1)$ & $O(0)$ & 10.3 & 10.3 \\
\hline P (Pro) & 75 & $5(1)$ & $0(0)$ & 5.3 & 5.3 \\
\hline$O$ (GIn) & 49 & $11(1)$ & $1(0)$ & 20.4 & 18.4 \\
\hline$R$ (Arg) & 66 & $7(1)$ & $2(0)$ & 9.1 & 6.1 \\
\hline S (Ser) & 61 & $15(1)$ & $O(0)$ & 23.0 & 23.0 \\
\hline T (Thr) & 63 & $34(0)$ & $\alpha(0)$ & 54.0 & 54.0 \\
\hline V (Val $\rangle$ & 103 & $2(0)$ & $O(0)$ & 1.9 & 1.9 \\
\hline$W(T r p)$ & 29 & $13(0)$ & $3(1)$ & 44.8 & 37.9 \\
\hline Y (Tyr) & 41 & $4(1)$ & $O(0)$ & 7.3 & 7.3 \\
\hline
\end{tabular}

* Values in parentheses denote the questionable $c_{n}$ cleavage assignments of the total specified

While other structural effects may also be important to the formation of $c_{n}$ ions, the effect of the residue C-terminal to the cleavage site is demonstrated dramatically in the CID spectra of two hexapeptides: ARVTAL and its analog ARVVAL. These peptides differ in structure solely in the nature of the side chain of the fourth residue, where the hydroxyl group of threonine in ARVTAL has been replaced with the methyl group of valine in ARVVAL. Although their CID spectra are essentially identical (except for the mass shift of the ions containing threonine), that of protonated ARVTAL (Figure 4a) shows a prominent $c_{3}$ fragment ion $(m / z 344)$ of approximately $25 \%$ abundance relative to the $a_{3}$ ion, while the same ion is absent from the spectrum of protonated ARVVAL (Figure $4 b$ ).

To probe the mechanism of $c_{n}$ ion formation in this case, the labile hydrogens on nitrogen and oxygen of

$\mathrm{T}>\mathrm{W}>\mathrm{K}>\mathrm{S}>\mathrm{Q}>\mathrm{C}>\mathrm{N}>\mathrm{L}>\mathrm{D}>\mathrm{Y}>\mathrm{F}>\mathrm{R}>\mathrm{P}>\mathrm{G}>\mathrm{E}>\mathrm{A}>\mathrm{H}>\mathrm{V}>\mathrm{I}>\mathrm{M}$

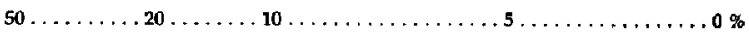
Figure 3. Amuino acid residues in descending order relative to the probability they occur C-terminal to $c_{n}$ cleavage (expressed as a percentage).
ARVTAL were exchanged with deuterium. The rates of amide hydrogen exchange in peptides are sensitive to conformational effects and experimental parameters such as $\mathrm{pH}$ and temperature $[15,16]$. Despite the use of experimental conditions suitable for full deuterium exchange and the use of $d_{8}$-glycerol as a FAB matrix, complete exchange of all 13 labile hydrogens could not be achieved. The molecular ion region of the spectrum of deuterated ARVTAL is represented in Figure 5.

Although only a degree of full deuteration could be achieved, selection of the ion at $m / z 644$ using the first mass spectrometer of the tandem instrument allows the $[M+D]^{+}$ion corresponding to $d_{13}$-ARVTAL solely to be subjected to collision. A region of the CID spectrum of $\left[\mathbf{d}_{13} \text {-ARVTAL }+\mathrm{D}\right]^{+}(m / z$ 644) surrounding the $c_{3}$ ion is shown in Figure 6. This spectrum shows peaks at $m / z 354$ and 355 in the ratio 3:2, corresponding to hydrogen and deuterium atom transfer accompanying $c_{3}$ cleavage, respectively. While hydrogen atom transfer accompanying $c_{3}$ cleavage appears to be the predominant mechanism, it is important to note that the ${ }^{13} \mathrm{C}$-species of the underdeuterated $\left(\mathrm{d}_{12}\right)$ component of the precursor ion selected for CID also contributes to this fragment ion. 

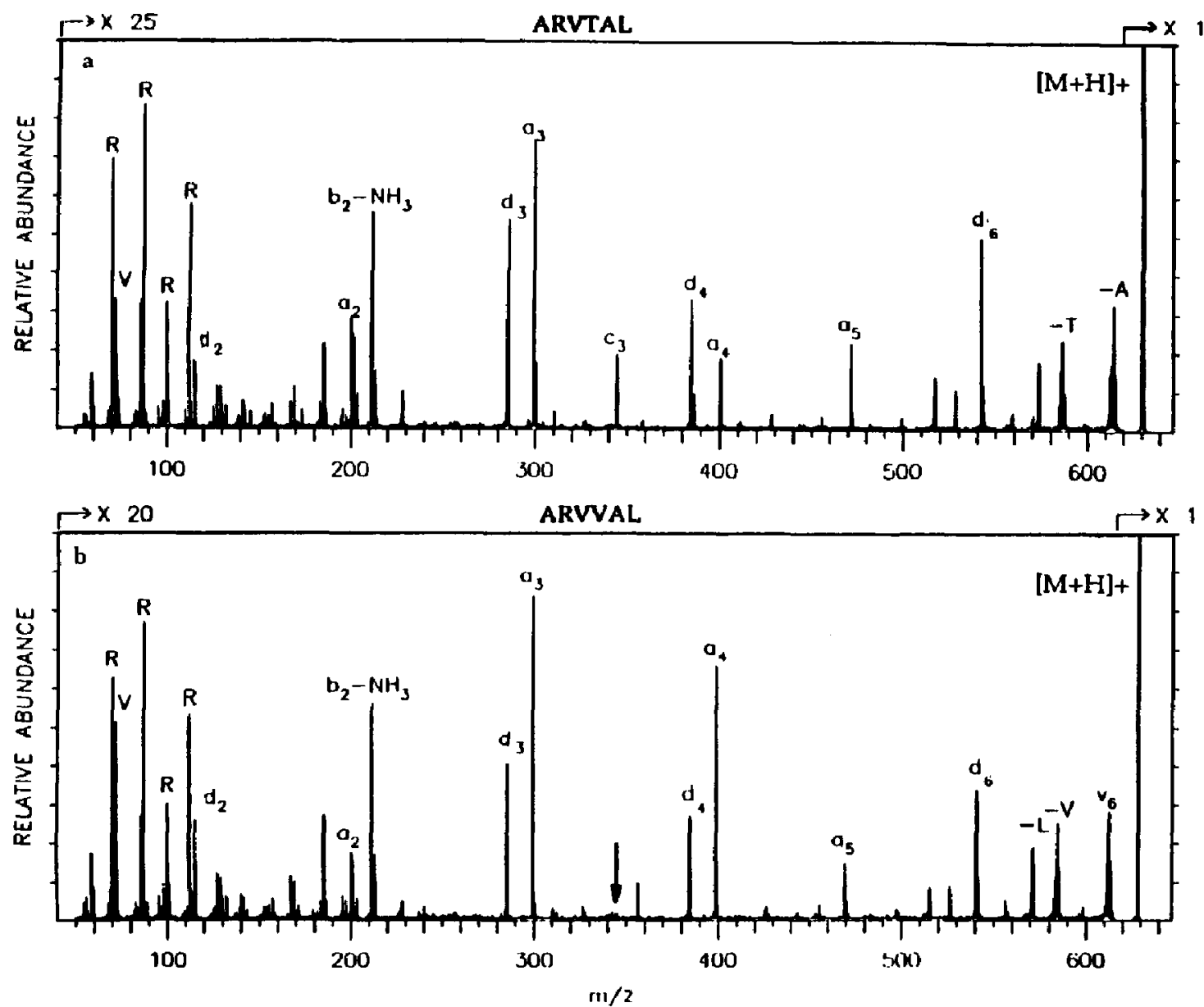

Figure 4. (a) CID spectrum of protonated ARVTAL; (b) CID spectrum of protonated ARVVAL (arrow indicates absence of $c_{3}$ ion at $m / z$ 344).

Although it is not possible to subtract this contribution from the $c_{3}$ fragment ion pattern without predicting a priori the mechanism of $c_{3}$ ion formation, it should be noted that the ion observed at $m / z 353$

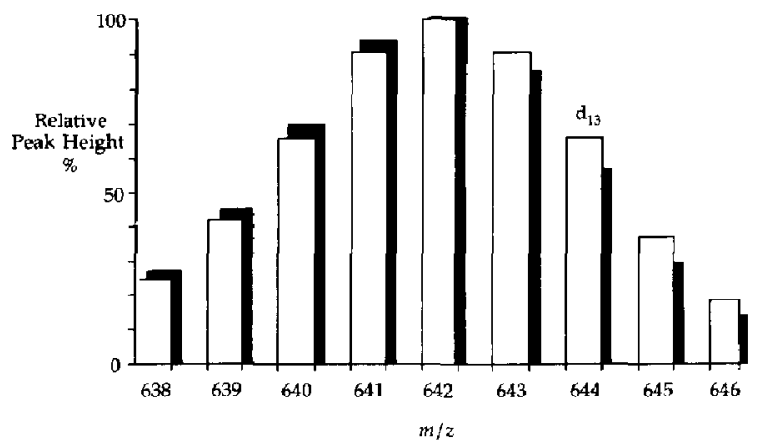

Figure 5. Representation of the molecular ion region of the mass spectrum of deuterated ARVTAL showing distribution corrected for natural ${ }^{13} \mathrm{C}$ isotopes. $\square=$ Experimental peak height distribution; $=$ distribution corrected for natural ${ }^{13} \mathrm{C}$ isotopes. arises solely from the ${ }^{13} \mathrm{C}$-contribution to the precursor ion. A simple calculation shows that this peak can only represent $a c_{3}$ ion from a precursor in which the $\mathrm{N}$-terminal portion of the peptide contains only 8 deuterium atoms $\left({ }^{12} \mathrm{C}_{14} \mathrm{H}_{20} \mathrm{D}_{8} \mathrm{~N}_{7} \mathrm{O}_{3} ; 350 \mathrm{Da}\right)$ and the ${ }^{13} \mathrm{C}$ atom is retained in the $\mathrm{C}$-terminal portion. This implies that all of the labile sites of the c-terminal portion are

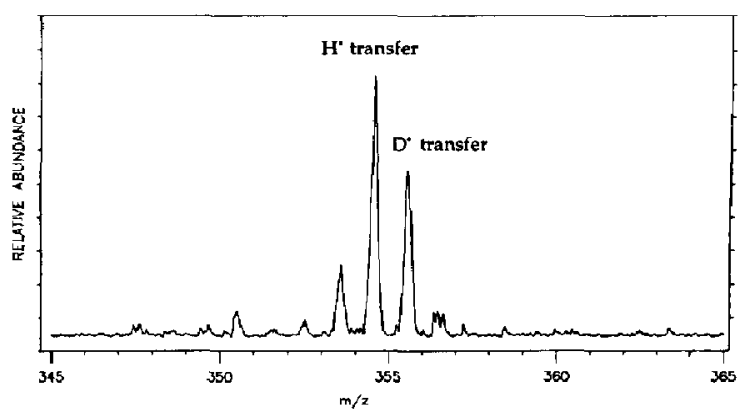

Figure 6. Region of CID spectrum of deuterated $d_{13}$-ARVTAL surrounding the $c_{3}$ ion. 
deuterated, and hence the $c_{3}$ ion subsequently formed must result from hydrogen atom transfer $\left({ }^{12} \mathrm{C}_{14} \mathrm{H}_{21} \mathrm{D}_{8} \mathrm{~N}_{7} \mathrm{O}_{3}+\mathrm{D}^{\prime} ; m / z 353\right)$.

These results suggest that hydrogen atom transfer from carbon is the predominant mechanistic pathway that accompanies $c_{n}$ cleavage, at least in the peptide studied. A proposed mechanism is shown in Figure 7. The transfer of a hydrogen atom from carbon in the case of threonine may also account for our observation that $c_{n}$ cleavage is favored next to other residues that do not contain a hydroxyl group, such as tryptophan and lysine. A similar conclusion has been made in a recent study for $c_{n}$ ion formation preceding valine [17], though the model tripeptide of this study appears to have been a poor choice given that valine does not promote $c_{n}$ ion formation based on our results (Figure 3). Indeed, this may explain why the authors observed a weak $c_{2}$ ion signal at this residue [17].

It has been shown so far that the amino acid Cterminal to a cleavage site plays an important role in the formation of $a c_{n}$ ion. In view of the mechanism proposed in Figure 7 , it is pertinent to consider how the nature of the residue following the fragmentation site might assist $c_{n}$ ion formation.

Groups that stabilize the developing $\mathrm{C}=\mathrm{C}$ double bond of the neutral fragment through conjugation or inductive effects would be expected to favor $c_{n}$ ion formation. From Figure 3, it can be seen that the aromatic residues tyrosine and phenylalanine promote $c_{n}$ ion formation to a similar degree, while the increased aromaticity of the indole group of tryptophan favors $c_{n}$ ion formation to a greater extent. One would also expect histidine to promote $c_{n}$ ion formation, but $\mathrm{C}_{\mathrm{n}}$ cleavage preceding a histidine residue occurs at less than $3 \%$ of the potential sites. One reason for this may be that histidine is a basic residue and consequently

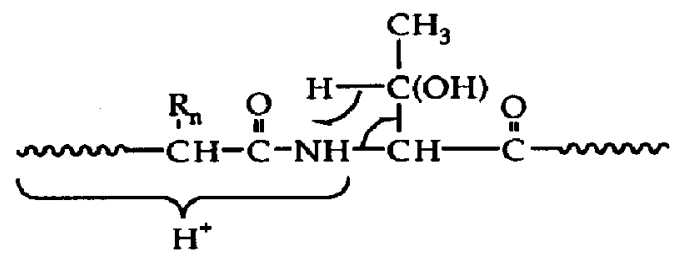

$H^{*}$ transfer

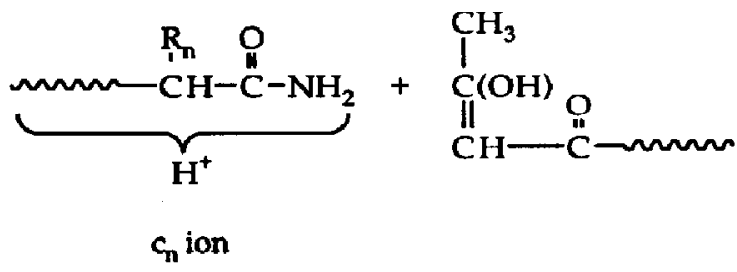

Figure 7. Proposed mechanism for the formation of a $c_{n}$ ion preceding a threonine residue. would be anticipated to direct the fragmentation of the peptide unfavorably from this site $(n+1)$ [9]. In accord, the basic residue arginine also does not facilitate $c_{n}$ ion formation when it resides at position $n+1$. These arguments, however, do not hold for lysine, and clearly our study to date does not address all the effects that may be important to $c_{n}$ ion formation.

The $\beta$-carbonyl-containing residues aspartic acid and asparagine promote $c_{n}$ ion formation to a similar degree, though this is not the case for analogs glutamic acid and glutamine, where the carbonyl group is remote from the developing $\mathrm{C}=\mathrm{C}$ double bond. Residues with heteroatoms in their side chains at the $\beta$ position, such as threonine and serine appear to promote $c_{n}$ ion formation as does cysteine to a lesser degree. The aliphatic residues, with no stabilizing groups in their side chains, are rarely found adjacent to $c_{n}$ cleavage. $C_{n}$ cleavage preceding a proline residue is hindered by the requirement that two bonds to the $\mathrm{N}$ atom be broken, and, indeed, proline appears low in the ranking of Figure 3.

The mechanism represented in Figure 7 would suggest that $c_{n}$ cleavage should never occur preceding glycine since this residue contains no $\beta$-hydrogen atoms. While $c_{n}$ cleavage adjacent to glycine does not occur readily, it was observed at approximately $5 \%$ of the potential sites (Figure 3). In these instances, hydrogen transfer is expected to occur from other sites towards the $\mathrm{C}$-terminus. Similar explanations have been used in the case of $d_{n}$ and $w_{n}$ ions [18, 19].

Despite the propensity for $c_{n}$ cleavage preceding threonine, such a cleavage is only observed at just over one half of the total number of potential sites of the sample set (Table 1, column IVb). However, as discussed earlier, $c_{n}$ cleavage preceding a threonine residue, or another residue that promotes $c_{n}$ cleavage, should be expected only for peptides whose fragmentation is N-terminally directed; that is, for peptides that bear a basic amino acid toward their $\mathrm{N}$-termini.

This prediction is supported by the data in Table 2, where several peptides of the sample set containing threonine are listed together with the nature of the fragment ions ( $\mathrm{N}$ - or C-terminal type) observed in the region of the spectrum of the predicted $c_{n}$ ion. From these data it is clear that peptides whose fragmentation is $\mathrm{N}$-terminally directed in the proximity of the threonine residue yield a $c_{n}$ ion by cleavage at threonine. In contrast, a peptide with C-terminally directed fragmentation at threonine would not be expected to yield a $c_{n}$ ion, while those peptides whose fragmentation is both $\mathrm{N}$ - and C-terminally directed at threonine may or may not yield a $c_{n}$ ion.

The observation that $c_{n}$ ions at threonine rarely appear, or have signals markedly suppressed, in peptides in which the residue is immediately preceded by proline appears to be a general one. Of the eight peptides of the sample set, including peptide VSEAMPTFL of Table 2, which contain a proline followed by a threonine residue, all show no $c_{n}$ ion at 
Table 2. Occurrence of $c_{n}$ ions in spectra of threonine-containing peptides

\begin{tabular}{|c|c|c|c|}
\hline $\begin{array}{l}\text { Peptide } \\
\text { Structure* }\end{array}$ & $\begin{array}{l}\text { Fragmentation } \\
\mathrm{N} \text {-terminally } \\
\text { directed near } \\
\text { threonine(s) }\end{array}$ & $\begin{array}{c}\text { Fragmentation } \\
\text { C-terminally } \\
\text { directed near } \\
\text { threonine(s) }\end{array}$ & $\begin{array}{c}\text { Presence of a } \\
c_{n} \text { ion(s) preceding } I\end{array}$ \\
\hline HSQGIF & + & - & + \\
\hline$(H C=0)-K L S I A A S F$ & + & - & + \\
\hline TINNDIIILL & + & - & + \\
\hline RPPGFIPFR & + & - & + \\
\hline NHLDNLKGIF & + & - & + \\
\hline THLLOGOSLILILE & + & - & + \\
\hline VHLIPVEK & + & + & + \\
\hline OVSLODKIGF & + & + & + \\
\hline EELTNK & + & + & - \\
\hline VSEAMPIFL & + & + & - \\
\hline (Ac)-VDAFLGIWK & + & + & - \\
\hline AIIYDA & - & + & - \\
\hline pyETSFIPRL-NH ${ }_{2}$ & - & + & - \\
\hline
\end{tabular}

* $(\mathrm{HC}=\mathrm{O})$ - and (Ac)- denote $\mathrm{N}$-terminal formyl and acelyl groups, respectively. pyE denotes a pyra-glutamic acid residue, $-\mathrm{NH}_{2}$ denotes a $\mathrm{C}$-terminal amide group.

threonine. These spectra, however, are frequently dominated by a $y_{n}$ ion at proline, and the high ion current associated with these fragments may play a role in the suppression of the $c_{n}$ ions.

Our study so far has shown that $c_{n}$ ion formation is favored when particular residues reside $\mathrm{C}$-terminal to the cleavage site (i.e., at position $\mathbf{n}+1$ of Figure 1 ) and the fragmentation is directed N-terminally in the vicinity of these residues. In view of this second requirement, we sought to address whether the residue $\mathrm{N}$ terminal to the cleavage site (i.e., at position $n$ of Figure 1) is particularly important to $c_{\mathrm{n}}$ ion formation. The same sample of 168 high-energy CID spectra were examined to correlate the occurrence of $c_{n}$ ions with the identity of the residue $X_{n} N$-terminal to the cleavage site. From this study, it was found that the nature of the residue $X_{n} N$-terminal to the cleavage site had little effect on $c_{n}$ ion formation. Cleavage leads to the formation of a $c_{n}$ ion at only $5-15 \%$ of the potential sites following most residues $X_{n}$, with the exception of tryptophan, proline, glutamine, and arginine. The probabilities that these residues reside $\mathrm{N}$-terminal to a site of cleavage are $0,1.3,18.8$, and $28.2 \%$, respectively. Of these, only arginine located $\mathrm{N}$-terminal to the cleavage site appears to promote $c_{n}$ ion formation to some extent, and this is likely to be a consequence of the residue's high basicity.

\section{Conclusions}

Efforts continue in this laboratory to unambiguously assign a peptide's primary structure based on its highenergy CID spectrum. To do so, it is important to account for as many product ions as possible in the spectrum and at the same time ascertain that the ion assignments are in accord with present knowledge concerning the presence and location of basic amino acids in the proposed sequence [9]. However, it is not uncommon for more than one sequence to be assigned to a CID spectrum with equal likelihood and thus, to date, computer algorithms designed to interpret CID spectra remain fallible. A knowledge of which fragment ions are more likely based on the proposed sequence may allow sequence ambiguities to be resolved.

In this study, the occurrence of $c_{n}$ ions was investigated. These ions appear more sequence specific than the remainder of the backbone fragment ions as they occur sporadically in high-energy CID spectra. It has been demonstrated that $c_{n}$ ion formation is favored at cleavage sites that are followed by threonine, and to a lesser extent tryptophan, lysine, and serine, where fragmentation is directed $\mathrm{N}$-terminally at these residues. In addition, we have shown that $c_{n}$ cleavage immediately preceding a threonine residue is accompanied, at least in part, by hydrogen transfer from carbon, and a mechanism for this process has been proposed. The nature of the residue $\mathrm{N}$-terminal to the cleavage site appears to contribute little specificity to $c_{n}$ ion formation.

A knowledge of the amino acid sequence prerequisites for the formation of $c_{n}$ ions should assist both the manual and computer-aided $[20,21]$ interpretation of high-energy CID spectra of peptides of unknown structure.

\section{Acknowledgments}

We are grateful to Dr. Ioannis Papayannopoulos, who compiled the collection of CID spectra used in this study. This work was supported by NIH research grants from the National Institutes of General Medical Sciences (GM05472) and the National Center for Research Resources (RR00317). 


\section{References}

1. Barber, M.; Bordoli, R. S.; Sedgwick, R. D; Tyler, A. N. J. Chem. Soc. Chem. Commut. 1981, 325-327.

2. Hunt, D. F.; Bone, W. M.; Shabanowitz, J.; Rhodes, J.; Ballard, J. M. Anal. Chem. 1981, 53, 1704-1708.

3. Lippstreu-Fisher, D. L.; Gross, M. Anal. Chem. 1985, 57, $1174-1180$.

4. Biemann, K. Anal. Chem. 1986, 58, 1289A-1300A.

5. Biemann, K. In Methods in Enzymology, Vol. 193; McCloskey, J. A., Ed.; Academic: San Diego, 1990; p 455.

6. Morris, H. M.; Panico, M.; Barber, M.; Bordoli, R. S.; Sedgwick, R. D.; Tyler, A.N. Biochem. Biophys. Res. Commun. 1981, 101, 623-631.

7. Williams, D. H.; Bradley, C.; Bojesen, G.; Santikarn, S.; Taylor, L. C. E. I. Am. Chem. Soc. 1981, 103, 5700-5704.

8. Biemann, K. Biomed. Environ. Mass Spectrom. 1989, 16, 99-101.

9. Martin, S. A,; Bjemann, K. Int. J. Mass Spectrom. Ion Processes $1987,78,213-218$

10. Roepstorff, P.; Fohlman, J. Biomed. Environ. Mass Spectrom. $1984,11,601$.

11. Falick, A. M.; Medzihradszky K. F.; Walls, F. C. Rapid Commun. Mass Spectram. 1990, 4, 318-322.
12. Bean, M. F.; Carr, S. A.; Thorne, G. C.; Reilly, M. H.; Gaskell, S. J. Anal. Chem. 1991, 63, 1473-1481.

13. Bordas Nagy, J.; Despeyroux, D.; Jennings, K. R. I. Am. Soc. Mass Spectrom. 1992, 3, 502-514.

14. Downard, K. M.; Papayannopoulos, I. A.; Biemann, K. In Proceedings of the 40th ASMS Conference on Mass Spectrometry and Allied Topics; Washington, DC, 1992; p 1789.

15. Molday, R. S.; Englander, S. W; Kallen, R. G. Biochemistry $1972,11,150-158$.

16. Thévenon-Emeric, G.; Kozlowski, J.; Zhang, Z.; Smith, D. L. Anal. Chem. 1992, 64, 2456-2458.

17. van Dongen, W. D.; de Koster, C. G.; Heerma, W.; Havenkamp, J. Rupiel Commun. Mass Spectrom. 1993, 7, 241-244.

18. Johnson, R. S.; Martin, S. A.; Biemann, K. Int. J. Mass Spectrom. Ion Processes 1988, 86, 137-154.

19. Johuson, R. S.; Martin, S. A.; Biemann, K.; Stults, J. T.; Watson, J. T. Anal. Chem. 1987, 56, 2621-2625.

20. Johnson, R. S.; Biemann, K. Biomed. Environ. Mass Spectrom. 1989, 18, 945-957.

21. Hines, W. M.; Falick, A. M.; Burlingame, A. M.; Gibson, B. W. J. Am. Soc. Mass Spectrom. 1992, 3, 326-336. 